\title{
A model for the consolidation of rafted sea ice
}

\author{
E. Bailey, ${ }^{1}$ D. L. Feltham, ${ }^{2,3}$ and P. R. Sammonds ${ }^{1,2}$ \\ Received 2 September 2008; revised 21 September 2009; accepted 27 October 2009; published 9 April 2010.
}

[1] Rafting is one of the important deformation mechanisms of sea ice. This process is widespread in the north Caspian Sea, where multiple rafting produces thick sea ice features, which are a hazard to offshore operations. Here we present a one-dimensional, thermal consolidation model for rafted sea ice. We consider the consolidation between the layers of both a two-layer and a three-layer section of rafted sea ice. The rafted ice is assumed to be composed of layers of sea ice of equal thickness, separated by thin layers of ocean water. Results show that the thickness of the liquid layer reduced asymptotically with time, such that there always remained a thin saline liquid layer. We propose that when the liquid layer is equal to the surface roughness the adjacent layers can be considered consolidated. Using parameters representative of the north Caspian, the Arctic, and the Antarctic, our results show that for a choice of standard parameters it took under $15 \mathrm{~h}$ for two layers of rafted sea ice to consolidate. Sensitivity studies showed that the consolidation model is highly sensitive to the initial thickness of the liquid layer, the fraction of salt release during freezing, and the height of the surface asperities. We believe that further investigation of these parameters is needed before any concrete conclusions can be drawn about rate of consolidation of rafted sea ice features.

Citation: Bailey, E., D. L. Feltham, and P. R. Sammonds (2010), A model for the consolidation of rafted sea ice, J. Geophys. Res., 115, C04015, doi:10.1029/2008JC005103.

\section{Introduction}

[2] Driving forces such as offshore winds and ocean currents can cause ice floes to collide, forming ridges or rafted sea ice. Ridges are elongated piles of rubble, and rafting is the overriding of one sheet by another. Various studies have investigated what conditions are favorable for rafting to take place as opposed to ridging [Hopkins et al., 1999; Parmerter, 1975; Tuhkuri and Lensu, 2002; Weeks and Kovacs, 1970]. These studies have shown that rafting is most common between thin ice sheets $(<0.3 \mathrm{~m})$ of uniform thickness. Two types of rafting have been identified: (1) simple rafting, where the two ice sheets interact along a straight edge and one sheet "simply" overrides the other, and (2) finger rafting, where the interacting sheets fracture along lines perpendicular to their interacting edge and form fingers. Alternate fingers are then overthrust and underthrust, leaving an interlocked structure [Vella and Wettlaufer, 2007; Vella and Wettlaufer, 2008; Weeks and Kovacs, 1970].

[3] Multiple rafting is also known to occur in some regions, where ice floes override one another multiple times to

\footnotetext{
${ }^{1}$ Rock and Ice Physics Laboratory, Department of Earth Sciences, University College London, London, UK.

${ }^{2}$ Centre for Polar Observation and Modelling, National Centre for Earth Observation, Department of Earth Sciences, University College London, London, UK.

${ }^{3}$ British Antarctic Survey, Cambridge, UK.

Copyright 2010 by the American Geophysical Union. 0148-0227/10/2008JC005103
}

produce thick sea ice features [Babko et al., 2002]. This process is particularly common in the north Caspian Sea, an area of particular interest because of its oil and gas reserves. Multiply rafted sections have been observed to contain up to 13 layers, all of roughly equal thickness, producing structures that are greater than $4 \mathrm{~m}$ in thickness (D. Mayne, personal communication, 2007). This phenomenon is also common in the Southern Ocean, where the sea ice thickness is usually less than a meter [Babko et al., 2002]. For example, Worby et al. [1996] analyzed 62 ice cores retrieved from 50 ice floes in the Bellinghausen and Amundsen seas and found that the floes with an average thickness of $0.9 \mathrm{~m}$ contained around eight distinct layers. In the Arctic, Melling et al. [1993] also observed that as many as four layers of ice were rafted in the southeastern Beaufort Sea to produce a total thickness of $\sim 6 \mathrm{~m}$.

[4] To date, rafting has not received as much attention in the literature as ridging. This is perhaps because ridge keels have been a greater concern for engineers [Hopkins et al., 1999], or perhaps it is due to the difficulties in identifying rafted ice thicker than $0.15-0.20 \mathrm{~m}$ in aerial imagery or of any other thickness in laser profiles or under ice sonar records [Babko et al., 2002].

[5] An ice feature can represent a zone of either weakness or strength in the ice pack depending on the degree of consolidation [Hoyland, 2002]. In a rafted section, the layers of sea ice are initially separated by thin layers of ocean water. The bonds between the layers are at first weak but may strengthen with time to produce a coherent ice sheet. Rafted sea ice is important from both a geophysical and an 
engineering point of view. From a geophysical perspective, rafted sea ice accounts for a significant fraction of the ice volume and may help determine the large-scale strength of the pack ice. In addition, it seems that rafting plays an important part in the mechanical redistribution of the sea ice thickness distribution [Babko et al., 2002; Toyota et al., 2004]. Poplin and Wang [1994] carried out extensive uniaxial compression tests on rafted ice samples collected in Norton Sound, Alaska. Their results showed that on ice samples cut horizontal to the crystal growth direction, at strain rates of $10^{-4}$ and $10^{-5} \mathrm{~s}^{-1}$, the mean strengths of consolidated rafted ice were actually larger (1.55 and $1.06 \mathrm{MPa}$ ) than the corresponding landfast samples (1.25 and $0.64 \mathrm{MPa})$. Since rafted ice loads are usually applied horizontally to offshore structures, this result implies that once consolidated, rafted ice may be a significant ice hazard. Therefore, the strength and thickness of rafted ice is also important in the design and operation of Arctic vessels and offshore structures [Hopkins et al., 1999].

[6] In this paper we present a one-dimensional, thermal consolidation model for rafted sea ice. We first consider the consolidation of two layers of rafted sea ice and then three layers of multiply rafted sea ice. The mathematical formulation of the consolidation model and the method of solution are described in section 2 . In section 3 , we present the parameters that are to be used in our simulations that are specific to the environments of the north Caspian Sea, the Arctic, and the Antarctic. In section 4, the results of the numerical simulations are presented, and the sensitivity of the model to certain parameters is examined. A discussion of the results and concluding remarks are presented in section 5 .

\section{Model Description}

[7] The consolidation model for rafted sea ice calculates how long it will take for the layers in a rafted section of sea ice to effectively bond into a coherent ice sheet. We consider the consolidation between the layers of both a two-layer and a three-layer section of rafted sea ice. The model is onedimensional, and we confine our attention to regions of rafted ice that extend over large enough distances that horizontal effects need not be taken into account. The rafted ice is assumed to be composed of layers of sea ice of equal thickness, separated by thin layers of ocean water. The thin layers of ocean water between the ice sheets are observed to initially form because large surface asperities or fragments of snow and ice caught between the ice sheets act as spacers, allowing seawater to flood in. Most samples collected of multiply rafted sea ice show that the layers in a rafted section are of roughly equal thickness. This suggests that the ice sheets rafted in quick enough succession that thermodynamic growth of the adjacent level ice could not have taken place during the same rafting event. Therefore, from the perspective of the model presented in section 2.1, multiple rafting took place simultaneously. In this section we describe the mathematical formulation and the method of solution of the consolidation model.

\subsection{Mathematical Formulation}

[8] We consider the situation where two identical ice sheets of initial thickness $H_{0}$ have rafted, such that there is a liquid layer of initial thickness $h_{0}$ located between adjacent sheets (Figure 1). The sea ice is described as a mushy layer, a rigid matrix of pure ice immersed in its brine [Feltham et $a l ., 2006]$, and the liquid layer is a thin layer of ocean water, trapped between the asperities of the ice sheets. The internal temperature of each ice sheet is determined from the nonlinear one-dimensional heat diffusion equation,

$$
c_{\mathrm{eff}} \frac{\partial T}{\partial t}=\frac{\partial}{\partial z}\left(k_{\mathrm{eff}} \frac{\partial T}{\partial z}\right)+A_{R}
$$

where $c_{\text {eff }}$ and $k_{\text {eff }}$ are the effective volumetric specific heat capacity and the thermal conductivity of sea ice (both functions of temperature), respectively, $T$ is the temperature within the ice sheet, $t$ is time, and $z$ is the vertical spatial coordinate, which is taken to be positive upward. The final term, $A_{R}$, describes the absorption of solar radiation that penetrates through the upper sea ice surface, which we take to be

$$
A_{R}=\kappa_{i} I_{0}(1-\alpha) F_{\mathrm{SW}} e^{-\kappa_{i} z},
$$

where $\kappa_{i}=1.5 \mathrm{~m}^{-1}$ is Beer's extinction coefficient, $I_{0}=0.4$ is the fraction of incident radiation that passes through the surface into the interior of the ice, $\alpha=0.6$ is the albedo for bare ice, and $F_{\mathrm{SW}}$ is the flux of incoming shortwave radiation [Ebert and Curry, 1993; Maykut and Untersteiner, 1971].

[9] The effective volumetric heat capacity and thermal conductivity of sea ice are given by [Bitz and Lipscomb, 1999; Feltham et al., 2006]

$$
c_{\mathrm{eff}}=c_{i}-\frac{T_{L}\left(S_{\text {bulk }}\right)-T_{L}(0)}{\theta^{2}} L
$$

and

$$
k_{\mathrm{eff}}=k_{\mathrm{bi}}-\left(k_{\mathrm{bi}}-k_{\mathrm{b}}\right) \frac{T_{L}\left(S_{\mathrm{bulk}}\right)-T_{L}(0)}{\theta},
$$

where $T_{\mathrm{L}}\left(S_{\text {bulk }}\right)$ is the liquidus (freezing) temperature of sea ice with a bulk salinity $S_{\text {bulk }}$, which we take to be uniform across the sheet, $T_{\mathrm{L}}(0)$ is the liquidus temperature of pure water, $\theta=T-T_{\mathrm{L}}(0), L=3.014 \times 10^{8} \mathrm{~J} \mathrm{~m}^{-3}$ is the volumetric heat of fusion of pure ice, $c_{i}=1.883 \times 10^{6} \mathrm{~J}\left(\mathrm{~m}^{3} \mathrm{~K}\right)^{-1}$ is the volumetric heat capacity of pure ice [Ebert and Curry, 1993 ], and $k_{\mathrm{bi}}$ and $k_{\mathrm{b}}$ are the conductivities of bubbly ice and brine, respectively.

[10] After Schwerdtfeger [1963], we take $k_{\mathrm{bi}}$ and $k_{\mathrm{b}}$ to be

$$
k_{\mathrm{bi}}=\frac{2 k_{\mathrm{i}}+k_{\mathrm{a}}-2 V_{\mathrm{a}}\left(k_{\mathrm{i}}-k_{\mathrm{a}}\right)}{2 k_{\mathrm{i}}+k_{\mathrm{a}}+V_{\mathrm{a}}\left(k_{\mathrm{i}}-k_{\mathrm{a}}\right)} k_{\mathrm{i}} \mathrm{W}(\mathrm{m} \mathrm{K})^{-1}
$$

and

$$
k_{\mathrm{b}}=0.4184\left(1.25+0.030 \mathrm{~K}^{-1} \theta+0.00014 \mathrm{~K}^{-2} \theta^{2}\right) \mathrm{W}(\mathrm{m} \mathrm{K})^{-1},
$$

where $k_{\mathrm{i}}=1.16\left(1.91-8.66 \times 10^{-3} \mathrm{~K}^{-1} \theta+2.97 \times 10^{-5} \mathrm{~K}^{-2}\right.$ $\left.\theta^{2}\right) \mathrm{W}(\mathrm{m} \mathrm{K})^{-1}$ is the conductivity of pure ice [Sakazume and Seki, 1978], $k_{\mathrm{a}}=0.03 \mathrm{~W}(\mathrm{~m} \mathrm{~K})^{-1}$ is the conductivity of air [Weeks and Ackley, 1986], and $V_{\mathrm{a}}=0.025$ is the fractional volume of air in sea ice [Timco and Frederking, 1996]. 


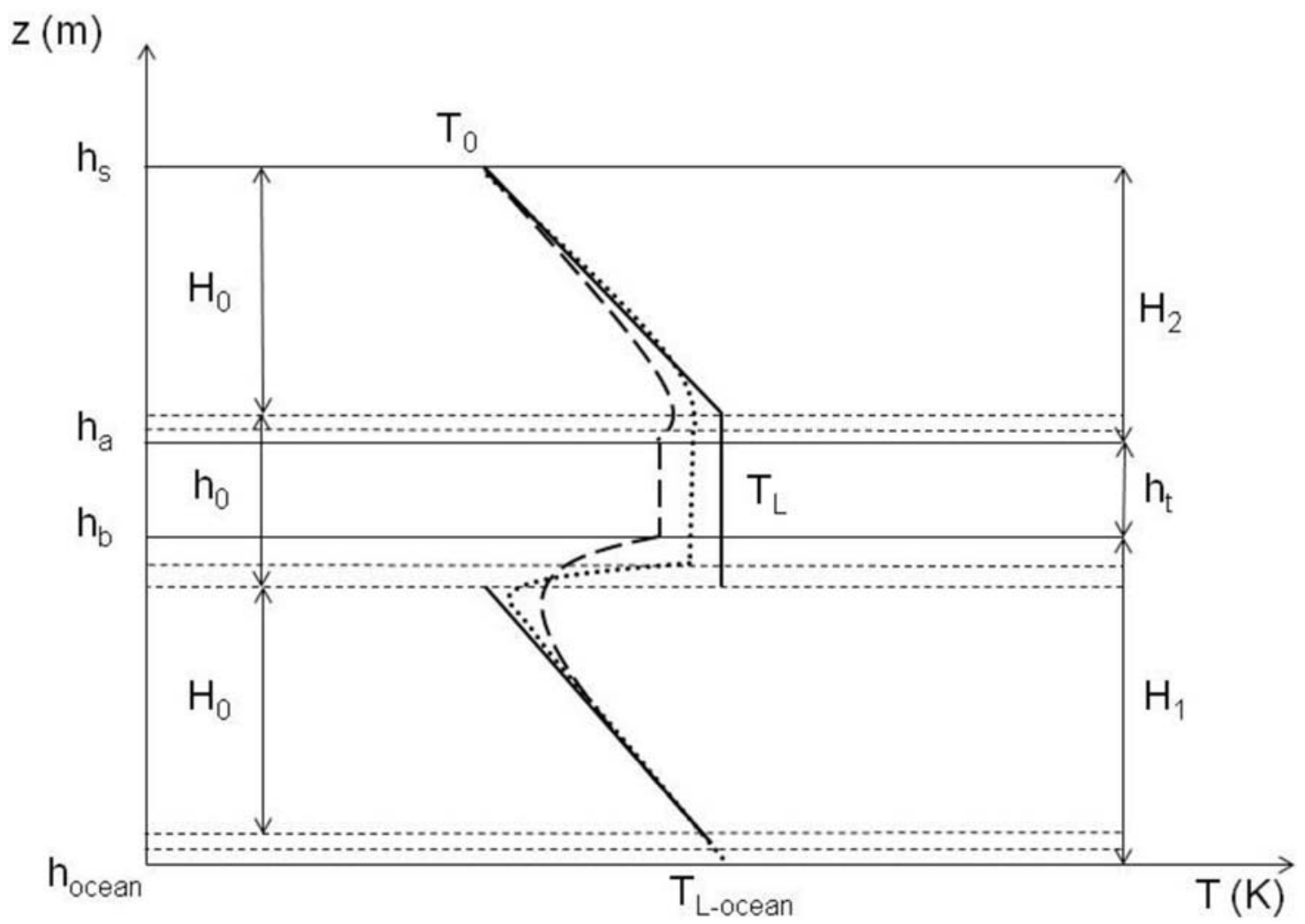

Figure 1. Schematic of the consolidation model illustrating how the temperature profiles, the thickness of the ice sheets, and the liquid layer evolve with time. $H_{0}$ and $h_{0}$ are the initial thicknesses of the ice sheets and the liquid layer, respectively, and $H_{1,2}$ and $h_{\mathrm{t}}$ are the thicknesses at a later time $t . T_{0}$ is the initial temperature at the ice-atmosphere interface, $T_{\mathrm{L}}$ is the liquidus temperatures in the liquid layer (and is also a function of time), and $T_{\mathrm{L}-\mathrm{ocean}}$ is the liquidus temperature of the ocean. The dashed lines at the interfaces between the ice sheets and the liquid layer and the lower ice sheet and the ocean indicate the movement of these interfaces due to freezing, where $h_{\mathrm{a}}$ is the location of the freezing front above the liquid layer, $h_{\mathrm{b}}$ is the location of the freezing front below the liquid layer, and $h_{\text {ocean }}$ is the location of the freezing front at the ice-ocean interface. The bolder lines denote the temperature profiles in the ice sheets and the liquid layer: the solid line depicts the initial temperature in the ice sheets and the liquid layer, and the dotted and dashed lines depict the temperature at later times.

[11] The sea ice is assumed to be in local thermodynamic equilibrium, which implies that the temperature $T$ and brine concentration $S_{\text {brine }}$ lie on the liquidus curve in the phase diagram for sea ice, i.e., $T=T_{\mathrm{L}}\left(S_{\text {brine }}\right)$. The liquidus curve can be approximated by the liquidus curve for sodium chloride solution [Notz et al., 2005; Weast, 1971],

$T_{\mathrm{L}}(S)=-5.33 \times 10^{-7} S^{3}-9.37 \times 10^{-6} S^{2}-0.0592 S+273.15 \mathrm{~K}$

We consider the ice sheets to initially have identical linear temperature profiles on the basis of the air and sea temperatures at the upper and lower boundaries (Figure 1), giving the following initial condition:

$$
T=\frac{T_{0}-T_{\mathrm{L}}\left(S_{\text {ocean }}\right)}{H_{0}} z+T_{\mathrm{L}}\left(S_{\text {ocean }}\right)(t=0),
$$

where $T_{0}$ is the temperature at the upper surface, $T_{\mathrm{L}}\left(\mathrm{S}_{\text {ocean }}\right)$ is the freezing temperature at the salinity of the ocean $S_{\text {ocean }}$, and $H_{0}$ is the initial thickness of the ice slabs.
[12] In the absence of surface melting, the net flux, $\left(F_{\text {net }}\right)_{0}$, at the upper surface of the rafted ice $\left(x=h_{s}\right)$, must balance the conductive flux, $-k_{\text {eff }} \partial T / \partial x$, at the surface, such that

$$
\begin{aligned}
\left(F_{\text {net }}\right)_{0} & \equiv \varepsilon_{\mathrm{i}}\left(F_{\mathrm{LW}}-\sigma T_{0}^{4}\right)+(1-\alpha)\left(1-I_{0}\right) F_{\mathrm{SW}}-F_{\text {sens }}-F_{\text {lat }} \\
& =-k_{\mathrm{eff}} \frac{\partial T}{\partial z}\left(z=h_{s}\right),
\end{aligned}
$$

where $\varepsilon_{\mathrm{i}}=0.99$ is the emissivity of bare ice, $F_{\mathrm{LW}}$ is the flux of downward longwave radiation, $\sigma=5.67 \times 10^{-8} \mathrm{~J}$ $\left(\mathrm{K}^{4} \mathrm{~m}^{2} \mathrm{~s}\right)^{-1}$ is the Stefan-Boltzmann constant, and $F_{\text {sens }}$ and $F_{\text {lat }}$ are the sensible and latent heat fluxes [Ebert and Curry, 1993; Maykut and Untersteiner, 1971; Taylor and Feltham, 2004].

[13] At the interior interfaces $\left(z=h_{\mathrm{a}}, h_{\mathrm{b}}\right)$, i.e., the interfaces above and below the liquid layer, the boundary conditions are

$$
T=T_{\mathrm{L}}\left(S_{\text {liquid }}\right)\left(z=h_{\mathrm{a}}, h_{\mathrm{b}}\right)
$$


and

$$
L \phi\left(\frac{\rho_{\text {brine }}}{\rho_{\text {ice }}}\right) \frac{d h}{d t}=k_{\text {eff }} \frac{\partial T}{\partial z}\left(\mathrm{z}=h_{\mathrm{a}}, h_{\mathrm{b}}\right),
$$

where $S_{\text {liquid }}$ is the salinity of the liquid layer, $\phi=1-S_{\text {bulk }} /$ $S_{\text {liquid }}$ is the local solid fraction per unit volume of the sea ice, $d h / d t$ is the velocity of the respective boundary, and $\partial T /$ $\partial z$ is the temperature gradient in the ice at the boundary.

[14] At the sea ice-ocean boundary $\left(z=h_{\text {ocean }}\right)$, the sea ice is held constant at the freezing temperature of the ocean,

$$
T=T_{L}\left(S_{\text {ocean }}\right)\left(z=h_{\text {ocean }}\right) .
$$

The ice growth rate at the ice-ocean boundary is given by the Stefan condition,

$$
L \phi\left(\frac{\rho_{\text {brine }}}{\rho_{\text {ice }}}\right) \frac{d h_{\text {ocean }}}{d t}=k_{\text {eff }} \frac{\partial T}{\partial z}+F_{\text {ocean }}\left(\mathrm{z}=h_{\text {ocean }}\right),
$$

where $F_{\text {ocean }}$ is the heat flux from the ocean directed into the base of the ice sheet. The adoption of a nonzero solid fraction at the sea ice-ocean interface, $\phi\left(z=h_{\text {ocean }}\right)=1-$ $S_{\text {bulk }} / S_{\text {ocean }}$, where $S_{\text {bulk }}$ is a constant, is an approximation in that $S_{\text {bulk }}$ will vary throughout the interface region [Notz and Worster, 2008]. Here the approximation implies we are tracking the location of the "consolidated" ice-ocean interface. This approximation conveys the mathematical advantage that the interface location can be determined explicitly (rather than using an implicit numerical technique) and leads to little numerical error [Feltham, 1998]. We have assumed that upon freezing, the liquid expanded by $9 \%$, i.e., $\rho_{\text {brine }}$ $\rho_{\text {ice }}=1.09$ [Pounder, 1965].

[15] Since the liquid layer is narrow, salt diffusion maintains a uniform salinity inside the liquid layer on the time scale of changes in diffusive heat flux in the surrounding ice sheets provided that $(h / H)^{2} \ll L e$, where $h$ is the liquid layer thickness, $H$ is the ice layer thickness, and $L e$ is the Lewis number, defined as the diffusion rate of salt divided by the effective thermal diffusivity of sea ice and equal to approximately $10^{-2}$ [Feltham, 1998]. For the calculations presented here, this condition is satisfied, and therefore, the temperature of the liquid layer $T_{\text {liquid }}$ is uniform and equal to the local liquidus temperature,

$$
T_{\text {liquid }}=T_{\mathrm{L}}\left(S_{\text {liquid }}\right) \text {. }
$$

[16] We assume that the liquid layer initially consists of ocean water, and as it freezes, a fraction $f^{\prime}$ of the salt originally contained in the seawater is released into the liquid layer. This assumption is based upon the observation that the liquid layer becomes increasingly salty as freezing progresses (see section 3). We believe that brine is released only from the freezing at the upper layer, so that conservation of salt implies

$$
S_{\text {liquid }}=S_{\text {ocean }}+f^{\prime} \frac{\Delta h_{\mathrm{a}}}{h_{\mathrm{t}}} S_{\text {ocean }},
$$

where $\Delta h_{\mathrm{a}}$ is the amount of freezing at the upper layer and $h_{\mathrm{t}}$ is the thickness of the liquid layer at time $t$. In the experiments described in section 3 it was impractical to measure $\Delta h_{\mathrm{a}}$, but the liquid layer thickness could be measured. Therefore, for the purposes of comparison with observations, and because the error it introduces is small compared with uncertainty in the measurement of the liquid layer salinity, we assume that $\Delta h_{\mathrm{a}}=f^{\prime \prime} \Delta h_{\mathrm{b}}$, where $f^{\prime \prime}$ is a constant and $\Delta h_{\mathrm{b}}$ is the amount of freezing at the lower layer. Then, since $\Delta h_{\mathrm{a}}=h_{0}-h_{\mathrm{t}}-\Delta h_{\mathrm{b}}$, we can rewrite conservation of salt as

$$
S_{\text {liquid }}=S_{\text {ocean }}+f S_{\text {ocean }}\left(h_{0} / h_{\mathrm{t}}-1\right),
$$

where $f=f^{\prime} /\left(1+f^{\prime \prime}\right)$. The rate of change of $h_{\mathrm{t}}$ can be deduced from the difference in the Stefan conditions at the boundaries above and below the liquid layer, so that

$$
\frac{d h_{\mathrm{t}}}{d t}=\frac{k_{\mathrm{eff}}}{\phi L} \frac{\rho_{\text {ice }}}{\rho_{\text {brine }}}\left(\frac{\partial T_{\mathrm{a}}}{\partial z}-\frac{\partial T_{\mathrm{b}}}{\partial z}\right),
$$

where $\partial T_{\mathrm{a}} / \partial z$ and $\partial T_{\mathrm{b}} / \partial z$ are the temperature gradients at the boundaries above $\left(z=h_{\mathrm{a}}\right)$ and below $\left(z=h_{\mathrm{b}}\right)$ the liquid layer, respectively. The system of equations (1)-(17) comprises a closed partial differential, initial boundary value problem.

[17] When considering the consolidation of three layers of rafted sea ice, we assume that the three layers are separated by two thin layers of ocean water that are initially of equal thickness. The mushy layer equations described above are used to determine the vertical heat transport within the ice sheets (equations (1)-(7)) and are subject to the same initial condition (equation (8)) and boundary conditions that describe the heat fluxes at the ice-atmosphere interface (equation (9)), the ice-liquid layer interfaces (equations (10) and (11)), and the ice-ocean interface (equations (12) and (13)). The rate at which the liquid layers reduce with time is then determined from the difference in the Stefan conditions at the respective interfaces (equation (17)).

\subsection{Method of Solution}

[18] The model described in section 2.1 was coded in MATLAB. The heat diffusion equation (equation (1)) was solved for each ice sheet using a grid spacing of $2 \mathrm{~mm}$ and a time step of $1 \mathrm{~s}$. Every $3 \mathrm{~s}$ the thickness of the liquid layers was calculated (equation (17)), and the local liquidus temperature (equation (14)), the solid fraction, and the thickness of the ice slabs were updated.

[19] Initial runs revealed that when the fraction of salt released into the liquid layer $(f)$ is greater than zero, the thickness of the liquid layers reduced asymptotically with time, such that there always remained a thin saline liquid layer. Complete solidification of the liquid layer will occur only if the temperature reaches the eutectic temperature of the seawater. We know from field observations that the layers of ice do, in fact, consolidate. Our model assumes that the surfaces of the ice slabs are smooth, whereas, in reality, they are rough. At some stage the surface asperities will grow sufficient in size to effectively bond the slabs together. We therefore imposed a "cutoff" in the program such that when the liquid layer reaches the size of the surface 
Table 1. Parameters Used for Our Model Calculation

\begin{tabular}{llll}
\hline Forcing Data & North Caspian Sea & Arctic & Antarctic \\
\hline$F_{\mathrm{LW}}\left(\mathrm{W} \mathrm{m}^{-2}\right)$ & $205^{\mathrm{a}}$ & $154.52^{\mathrm{b}}$ & $158^{\mathrm{c}}$ \\
$F_{\mathrm{SW}}\left(\mathrm{W} \mathrm{m}^{-2}\right)$ & $76^{\mathrm{a}}$ & $0^{\mathrm{b}}$ & $0^{\mathrm{c}}$ \\
$\left.F_{\text {sens }}(\mathrm{W} \mathrm{m})^{-2}\right)$ & $3^{\mathrm{a}}$ & $5.7^{\mathrm{b}}$ & $43^{\mathrm{c}}$ \\
$F_{\text {lat }}(\mathrm{W} \mathrm{m})^{-2}$ & $-1^{\mathrm{a}}$ & $0.5^{\mathrm{b}}$ & $-3^{\mathrm{c}}$ \\
$F_{\text {ocean }}\left(\mathrm{W} \mathrm{m}{ }^{-2}\right)$ & 9.7 & $3^{\mathrm{d}}$ & $3^{\mathrm{d}}$ \\
$\mathrm{S}_{\text {ocean }}(\mathrm{ppt})$ & 6 & 33 & 35 \\
$\mathrm{~S}_{\text {bulk }}(\mathrm{ppt})$ & 1 & 5 & 5 \\
$f(\%)$ & 27 & 27 & 27 \\
$h_{\text {sa }}(\mathrm{mm})$ & 0.5 & 0.5 & 0.5 \\
$h_{0}(\mathrm{~mm})$ & 5 & 5 & 5 \\
$H_{0}(\mathrm{~m})$ & 0.2 & 0.2 & 0.2
\end{tabular}

${ }^{\mathrm{a}}$ Mean for January 2008 provided by the National Centers for Environmental Prediction (NCEP).

${ }^{\mathrm{b}}$ Mean for December 1998 taken from atmospheric SHEBA data.

${ }^{\mathrm{c}}$ Mean for July 2007 provided by NCEP.

${ }^{\mathrm{d}}$ Perovich and Elder [2002].

asperities $\left(h_{\mathrm{sa}}\right)$, the adjacent ice sheets can be considered consolidated.

\section{Model Parameters}

[20] The model was run using parameters typical to the environments of the north Caspian Sea, the Arctic, and the Antarctic (see Table 1). Constant values were used for the forcing data $\left(F_{\mathrm{LW}}, F_{\mathrm{SW}}, F_{\text {sens }}, F_{\text {lat }}, F_{\text {ocean }}\right)$, the ocean salinity $\left(S_{\text {ocean }}\right)$, and the bulk salinity of the sea ice $\left(S_{\text {bulk }}\right)$.
The atmospheric data $\left(F_{\mathrm{LW}}, F_{\mathrm{SW}}, F_{\text {sens }}, F_{\text {lat }}\right)$ were calculated from averages of the coldest months in the respective locations, using data collected during the Surface Heat Budget of the Arctic Ocean (SHEBA) experiment for the Arctic and the National Centers for Environmental Prediction for the north Caspian and the Antarctic. The oceanic heat flux $\left(F_{\text {ocean }}\right)$ was set to $3 \mathrm{~W} \mathrm{~m}^{-2}$ for the Arctic and the Antarctic and $9.7 \mathrm{~W} \mathrm{~m}^{-2}$ for the north Caspian. These values were based on data collected over first-year sea ice in the Arctic between November 1997 and February 1998 as part of the SHEBA project [Perovich and Elder, 2002] and data collected in the north Caspian Sea.

[21] The fraction of salt $(f)$ that is released into the liquid layer from the freezing interfaces was calculated from a series of consolidation experiments that were carried out on rafted sea ice in the Hamburg Ship Model Basin (HSVA). Salinity measurements were made of the upper liquid layer of a three-layer section of multiply rafted sea ice by drilling a hole down to the layer and sampling the liquid with a pipette. The salinity and temperature of the sample were then recorded using the WTW conductometer (LF191). The results of this experiment showed that as the thickness of the liquid layer decreased, the salinity of the layer gradually increased. From conservation of salt, $f$ was calculated from

$$
f=\frac{S_{t}-S_{\text {ocean }}}{S_{\text {ocean }}} \frac{1}{h_{0} / h_{\text {sa }}-1},
$$

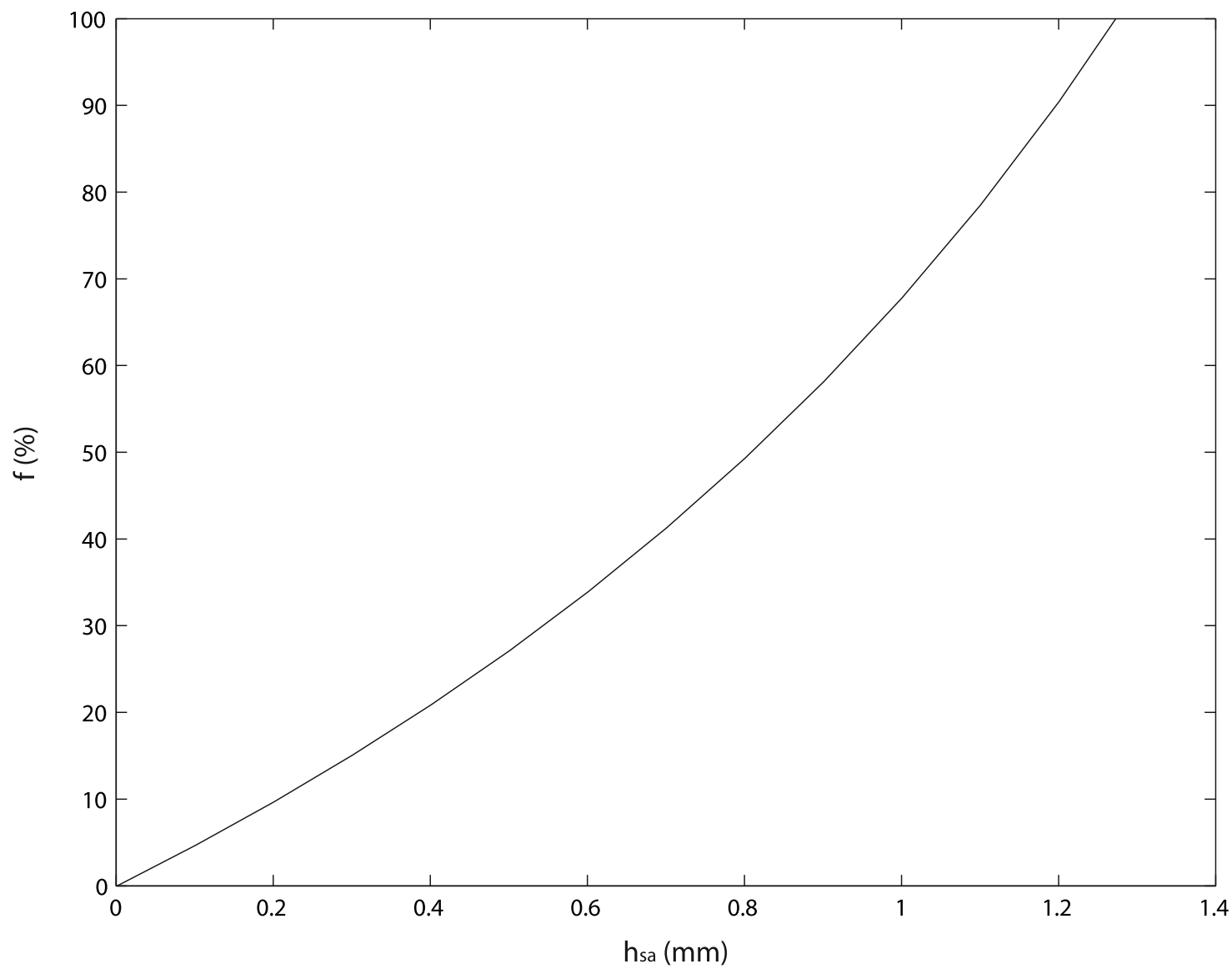

Figure 2. Dependence of the fraction of salt released $(f)$ into the liquid layer on the surface asperity height $\left(h_{\mathrm{as}}\right)$, based on data collected during the HSVA ice tank experiments. 
Table 2. Results for the Rate of Consolidation of Two Layers of Rafted Sea Ice

\begin{tabular}{lc}
\hline Location & Rate of Consolidation (min) \\
\hline Caspian Sea & 80 \\
Arctic & 891 \\
Antarctic & 542 \\
\hline
\end{tabular}

where $S_{t}=77.3$ parts per thousand (ppt) is the concentration of the liquid layer immediately prior to the upper two layers of ice becoming consolidated, $S_{\text {ocean }}=32.8 \mathrm{ppt}$ is the concentration of the tank water prior to commencing the experiment, $h_{0}=3 \mathrm{~mm}$ is the initial thickness of the liquid layer, and $h_{\mathrm{sa}}$ is the surface asperity height. The mechanism by which a fraction of the salt is released from the sea ice formed as the liquid layer freezes is not entirely clear. We speculate that the mechanism involved is brine convection highly localized to the vicinity of the interface between the ice and liquid layer, probably at a length scale of the order of the crystal spacing itself. Brine convection is discussed in more detail by Notz and Worster [2008].

[22] A plot of $h_{\mathrm{sa}}$ versus $f$ is shown in Figure 2. The plot shows that on the basis of equation (18) the surface asperity height lies in the range of 0 to $1.27 \mathrm{~mm}$. For our simulations, $h_{\text {sa }}$ was set to $0.5 \mathrm{~mm}$, making the fraction of salt released $f$ equal to $27 \%$ ( $f^{\prime}$ is approximately twice this value if one considers salt release only from freezing at the upper surface

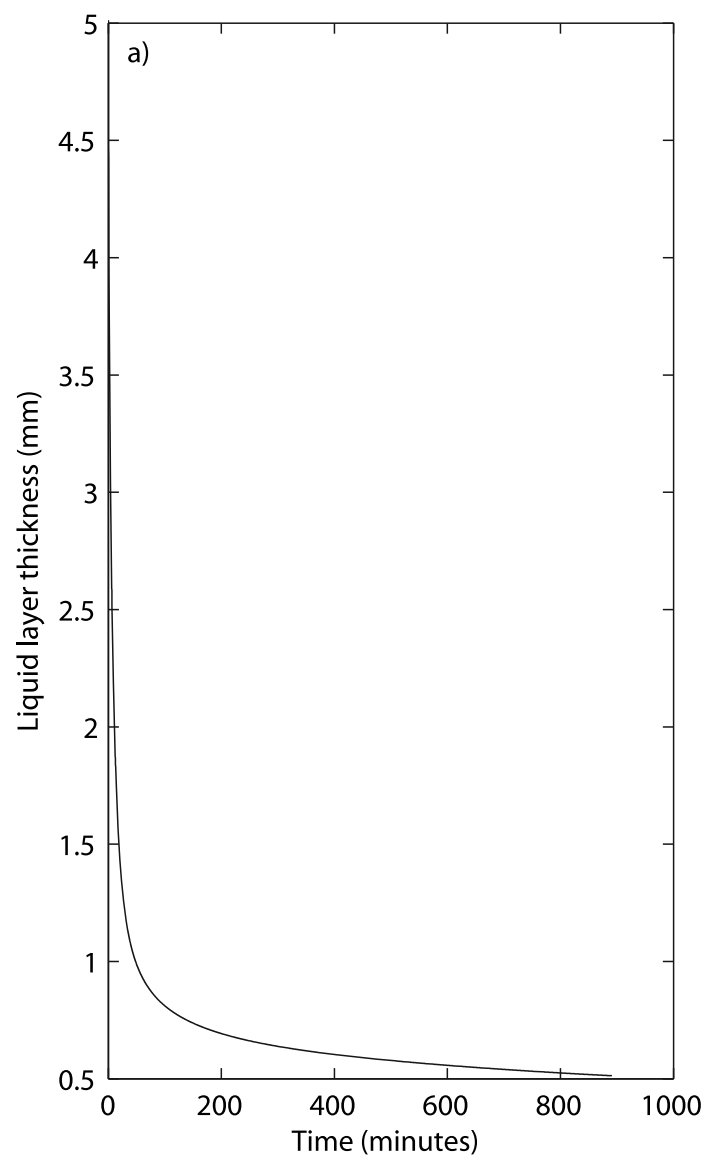

of the liquid layer and roughly equal freezing rates at the upper and lower interfaces).

\section{Numerical Simulations}

[23] In this section we present the results of our simulations. First, we describe the results for simple rafting and then multiple rafting. After this we present a series of sensitivity tests that were performed in order to test the model's sensitivity to certain parameters.

\subsection{Simple Rafting}

[24] The model was run for two layers of simply rafted sea ice using parameters typical of the environments of the north Caspian, the Arctic, and the Antarctic (see Table 2). The results show that the ice sheets all consolidated in under 15 $\mathrm{h}$ (900 $\mathrm{min})$. The quickest rate was by far the north Caspian, followed by the Antarctic, and then, finally, the Arctic.

[25] Figure 3 shows the variation in the thickness of the liquid layer and its temperature with time. Figure 3 shows that as the thickness of the liquid layers reduces, so does the temperature of the liquid layer. This is because as the liquid layer freezes, increasing amounts of salt are released into the liquid layer, therefore reducing its freezing temperature. Figure $3 \mathrm{~b}$ shows that prior to consolidation, the temperature of the liquid layer reduced to $265.5 \mathrm{~K}\left(-7.65^{\circ} \mathrm{C}\right)$, which

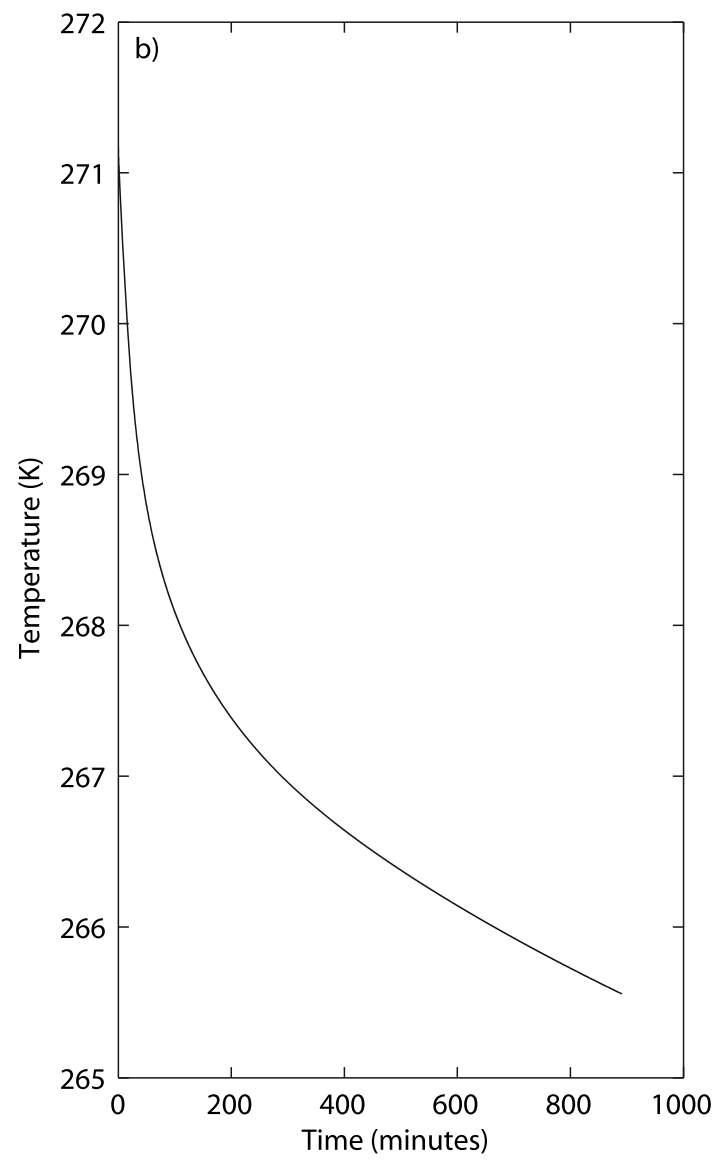

Figure 3. The evolution of (a) the thickness of the liquid layer and (b) the temperature in the liquid layer with time, using parameters representative of the Arctic. 


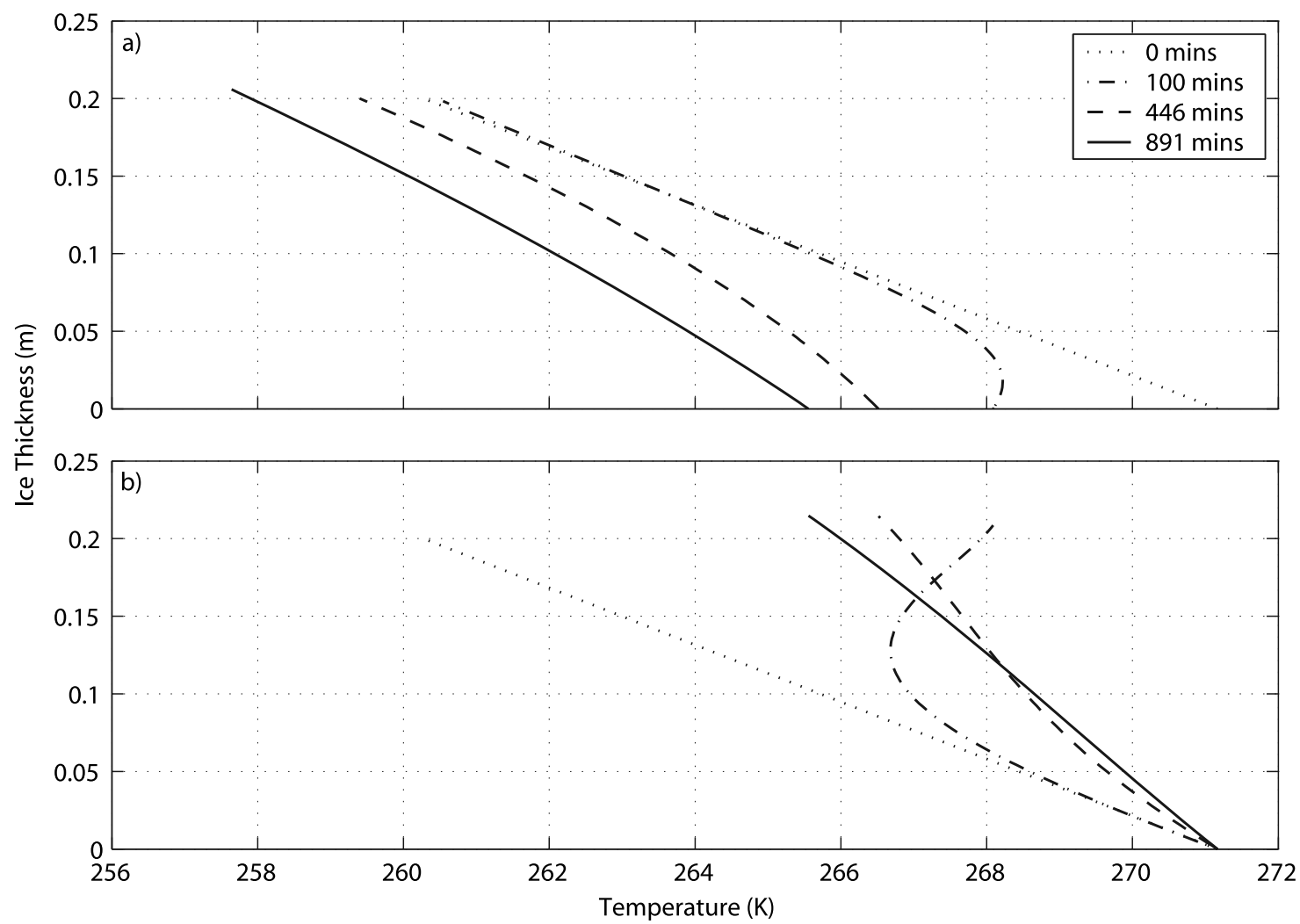

Figure 4. The evolution of the temperature profiles in a two-layer rafted section of sea ice using parameters representative of the Arctic: (a) the ice sheet that is in contact with the atmosphere and (b) the ice sheet that is in contact with the ocean. The dotted line shows the initial condition, the dashed-dotted line shows the temperature at $100 \mathrm{~min}$, the dashed line shows the temperature at $446 \mathrm{~min}$, and the solid line shows the temperature profile when the liquid layer has consolidated (at $891 \mathrm{~min}$ ).

corresponds to salinity of $113 \mathrm{ppt}$ (calculated by inverting equation (7)).

[26] Figure 4 shows the evolution of the temperature profiles in each ice sheet for the Arctic. This is of interest because the rate of consolidation is dependent on the temperature gradient on either side of the liquid layer (equation (17)). Figure 4a represents the ice sheet that is in contact with the atmosphere, and Figure $4 \mathrm{~b}$ represents the ice sheet that is in contact with the ocean. The dotted line shows the initial condition, and the solid line shows the temperature profile when the upper layer has consolidated. Figure 4 shows that the temperature in the ice sheets is initially linear and then gradually evolves to reestablish an almost linear temperature profile throughout the two ice sheets.

\subsection{Multiple Rafting}

[27] In this section we present the results for a three-layer, multiply rafted section of sea ice (see Table 3 ). The results show that using parameters representative of the north Caspian Sea, it took $80 \mathrm{~min}$ for the ice sheets to consolidate, whereas when using Arctic and Antarctic parameters it took significantly longer to freeze. This is principally due to the differences in the salinity of the ocean and the sea ice. In each case the upper liquid layer froze faster than the lower layer did, which is as we would expect as the upper layer is close to the colder temperatures of the atmosphere. The time difference in the case of the north Caspian is, however, very small, indicating that there are enough cold reserves within the ice sheets to freeze both liquid layers almost simultaneously, which might explain why multiple rafting is a predominant ice hazard in the region. It is also interesting to note that in the cases of the Arctic and the Antarctic the consolidation time for the upper liquid layer was $\sim 0.7$ times shorter than the consolidation time for two layers of rafted ice (comparing Tables 2 and 3), indicating the effect that the oceanic heat flux and ocean temperature have on the consolidation process.

[28] Figure 5 shows the evolution of the temperature profiles in three layers of multiply rafted sea ice using parameters representative of the Arctic. Figure 5a represents the ice sheet that is in contact with the atmosphere, Figure $5 \mathrm{~b}$ represents the ice sheet that is in the center of the rafted section, and Figure 5c represents the ice sheet that is in

Table 3. Results for the Rate of Consolidation of Three Layers of Multiply Rafted Sea Ice

\begin{tabular}{lcc}
\hline & \multicolumn{2}{c}{ Rate of Consolidation (min) } \\
\cline { 2 - 3 } Model Run & Upper Liquid Layer & Lower Liquid Layer \\
\hline Caspian Sea & 78 & 80 \\
Arctic & 640 & 2198 \\
Antarctic & 423 & 1783 \\
\hline
\end{tabular}



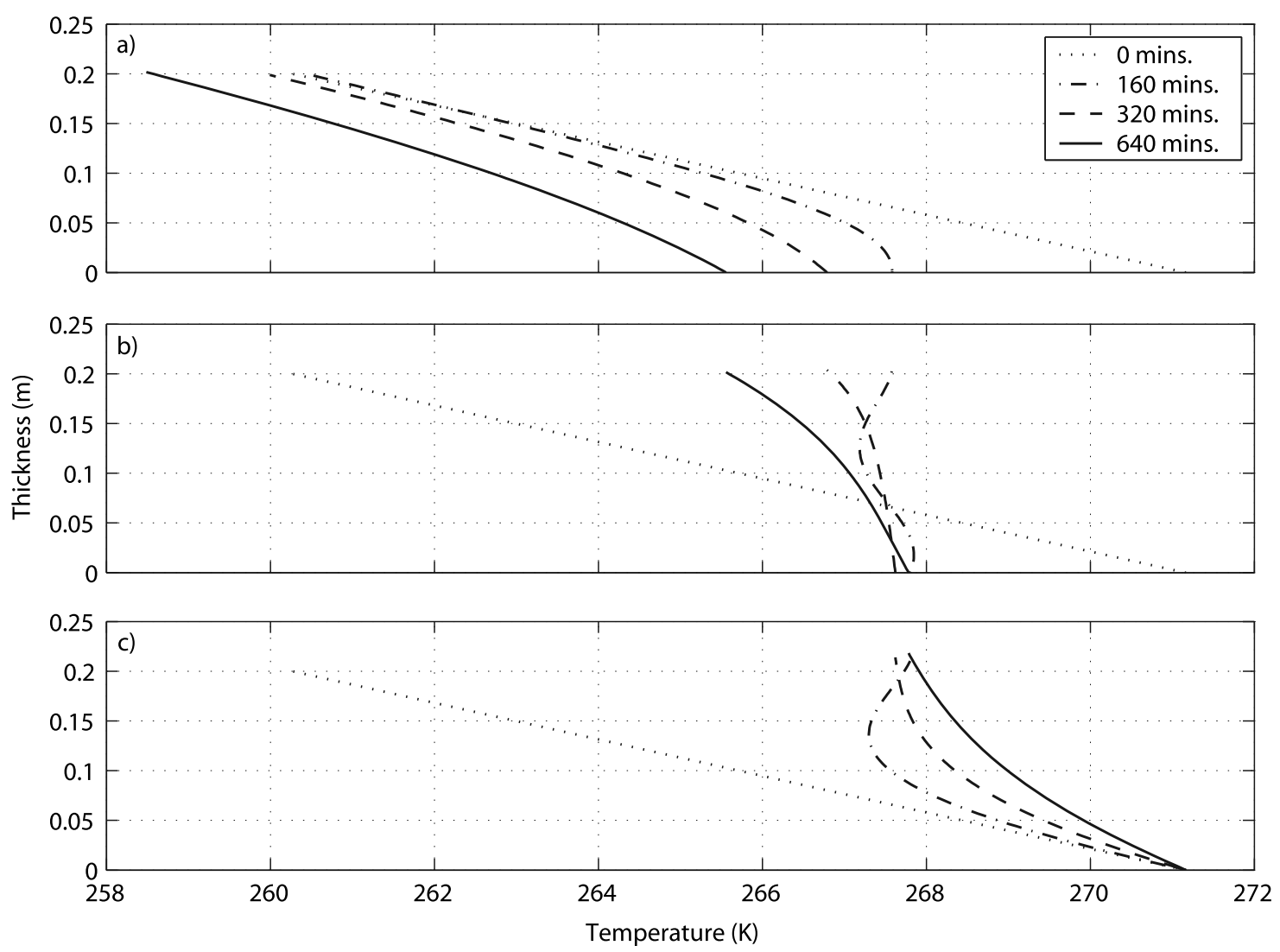

Figure 5. The evolution of the temperature profiles in a three-layer section of rafted sea ice using parameters specific to the Arctic: (a) the ice sheet that is in contact with the atmosphere, (b) the ice sheet that is in the center of the rafted section, and (c) the ice sheet that is in contact with the ocean. The dotted line shows the initial condition, the dashed-dotted line shows the temperature at $160 \mathrm{~min}$, the dashed line shows the temperature at $320 \mathrm{~min}$, and the solid line shows the temperature profile when the upper layer has consolidated (at $640 \mathrm{~min}$ ).

contact with the ocean. The dotted line shows the initial condition, and the solid line shows the temperature profile when the upper layer consolidated. Figure 5 shows that the temperature at the upper liquid layer decreases with time until it consolidates at $640 \mathrm{~min}$. The adjacent ice sheets were then merged, and the program continued until the lower liquid layer consolidated (see Figure 6). Figure 6 shows that the temperature of the lower liquid layer is now decreasing with time until it freezes after 2198 min.

\subsection{Sensitivity Studies}

[29] Since it is the first time that the consolidation of rafted sea ice has been investigated numerically, it is important to investigate the model's sensitivity to certain parameters that are not well known. To do such an analysis, a standard case must first be chosen, which we take to be the parameters for the Arctic listed in Table 1. In each sensitivity study, multiple runs were made, varying one parameter at a time, within a conceivable range, while holding the others constant at the standard case values. The parameters we examine are the initial liquid layer thickness $h_{0}$, the initial ice thickness $H_{0}$, the bulk salinity of the sea ice $\mathrm{S}_{\text {bulk, }}$, the salinity of the ocean $S_{\text {ocean }}$, the fraction of salt released into the liquid layer $f$, the surface asperity height $h_{\mathrm{sa}}$, and the forcing data $\left(F_{\mathrm{LW}}, F_{\mathrm{SW}}, F_{\text {sens }}, F_{\text {lat }}, F_{\text {ocean }}\right)$.
[30] The dependence of the consolidation time $\left(C_{\text {time }}\right)$ on $h_{0}, H_{0}, \mathrm{~S}_{\text {bulk }}, S_{\text {ocean }}, f$, and $h_{\text {sa }}$ is shown in Figure 7. Figure $7 \mathrm{a}$ shows the dependence of $C_{\text {time }}$ on $h_{0}$. Figure $7 \mathrm{a}$ shows that the larger $h_{0}$ is, the longer $C_{\text {time }}$ is. When $h_{0}$ is below $3 \mathrm{~mm}, C_{\text {time }}$ is very rapid, and for thicknesses greater than $4 \mathrm{~mm}, C_{\text {time }}$ increases by almost a factor of 3 for every millimeter increase in $h_{0}$. For values greater than $6 \mathrm{~mm}$, model runs showed the liquid layer did not consolidate and started to rise after about $6000 \mathrm{~min}$ (see Figure 8). Figure 9 shows the temperature profiles for when $h_{0}$ was set to $7 \mathrm{~mm}$. The solid lines show the temperature profiles in the ice sheets when the liquid layer thickness started to increase (at $5847 \mathrm{~min}$ ). At this point, the temperature profiles are linear and of negative gradient, which promotes "melting" at the top of the lower ice sheet and freezing at the base of the upper ice sheet. We put the term melting in quotation marks because what is driving the phase change is the difference in salinity of the liquid layer and ice sheet; technically, the lower ice layer is said to dissolve, rather than melt [Woods, 1992]. What drives the heat transport into the liquid layer is the fact that the temperature of the liquid layer, being at the liquidus temperature appropriate to its high salinity, is lower than the temperature in the lower ice sheet. Sensible heat is extracted from the lower ice layer and converted into the latent heat of the liquid phase. Since the base of the ice sheet 

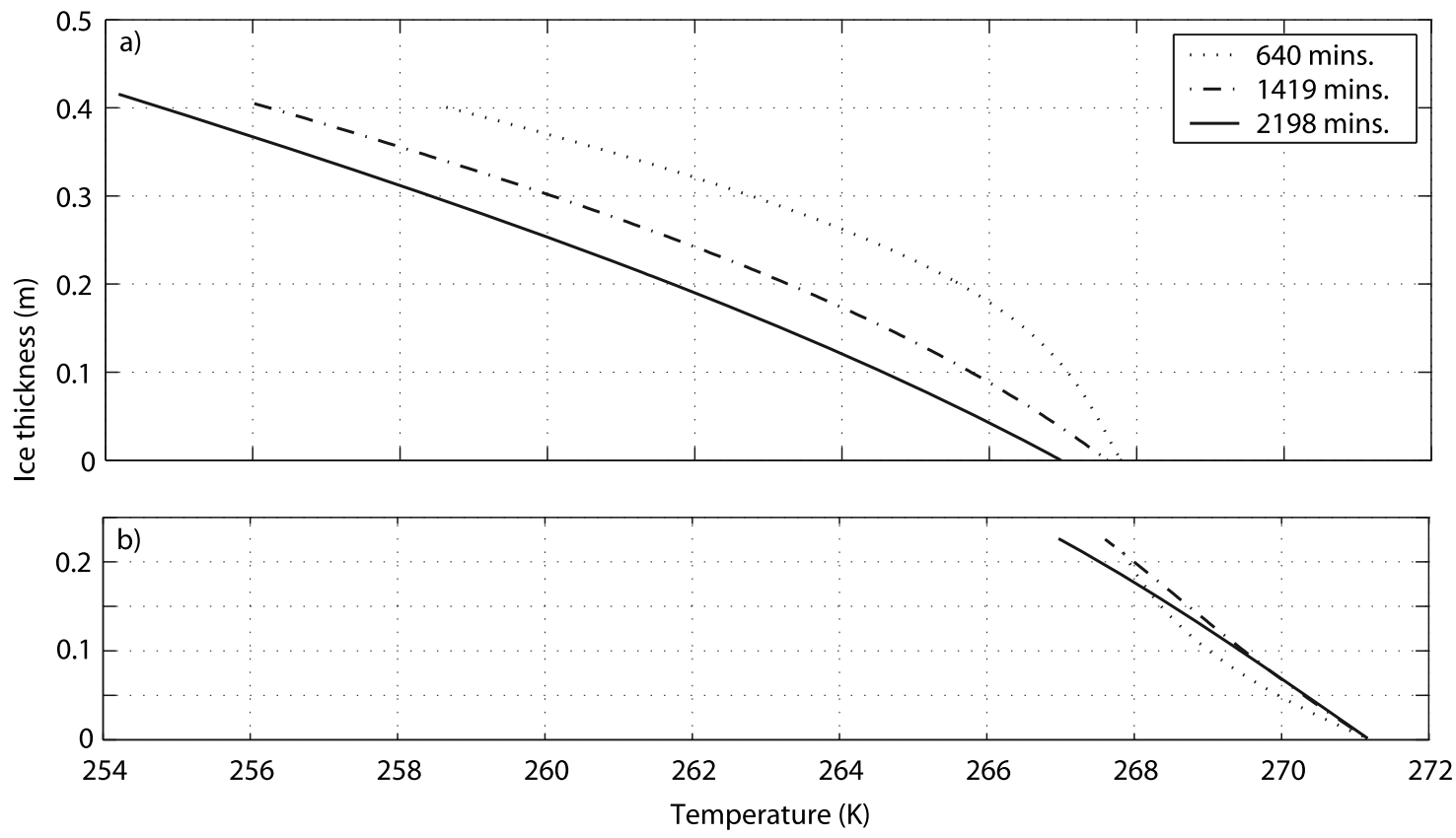

Figure 6. The evolution of the temperature profiles after the top two ice sheets shown in Figure 4 have frozen together: (a) the consolidated top two ice sheets and (b) the remaining ice sheet that is in contact with the ocean. The dotted line shows the temperature profile when the upper liquid layer consolidated (640 min), the solid line shows the temperature when the bottom liquid layer consolidated (2198 min), and the dashed line is midway between these two points $(1419 \mathrm{~min})$.

above the liquid layer is freezing and the top of the ice sheet below the liquid layer is melting, the liquid layer is migrating downward. To investigate this, we plotted the location of the freezing fronts with time (see Figure 10). Figure 10 shows that after an initial rise both liquid layers have migrated downward by $\sim 0.1 \mathrm{~m}$ in about $6000 \mathrm{~min}$.
[31] Figure 7b shows the dependence of $C_{\text {time }}$ on $H_{0}$. Figure $7 \mathrm{~b}$ shows that at both large and small ice layer thicknesses, the consolidation time increases. At large $H_{0}$ this is due to the reduced extraction of heat from the liquid layer to the atmosphere through the upper ice layer. At low $H_{0}$, the rate of diffusion of heat from the ocean into the
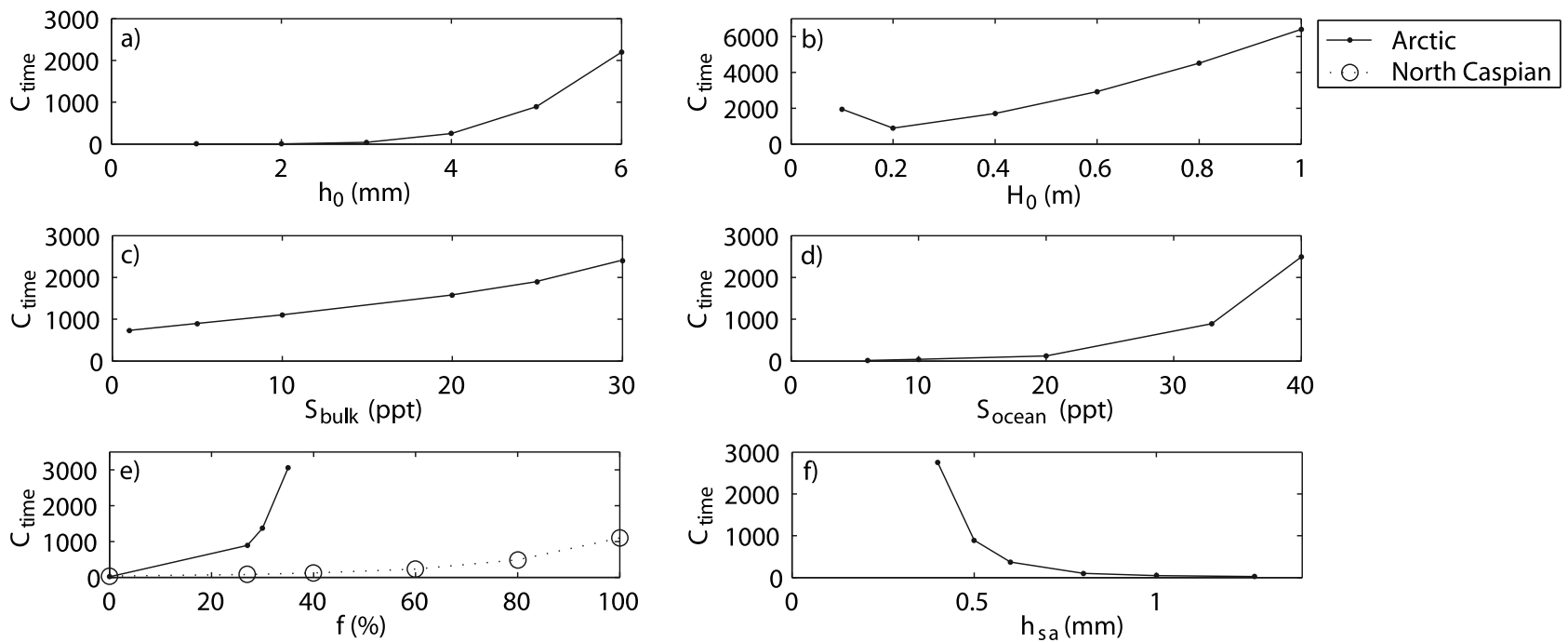

Figure 7. Dependence of the consolidation time $\left(C_{\text {time }}\right)$ in minutes on (a) the initial liquid layer thickness $h_{0}$, (b) the initial ice thickness $H_{0}$, (c) the bulk salinity of the sea ice $\mathrm{S}_{\text {bulk }}$, (d) the salinity of the ocean $S_{\text {ocean }}$, (e) the fraction of salt released into the liquid layer $f$, and (f) the surface asperity height $h_{\mathrm{sa}}$. The solid line and the dashed line show the simulations run with parameters specific to the Arctic and the north Caspian, respectively. 


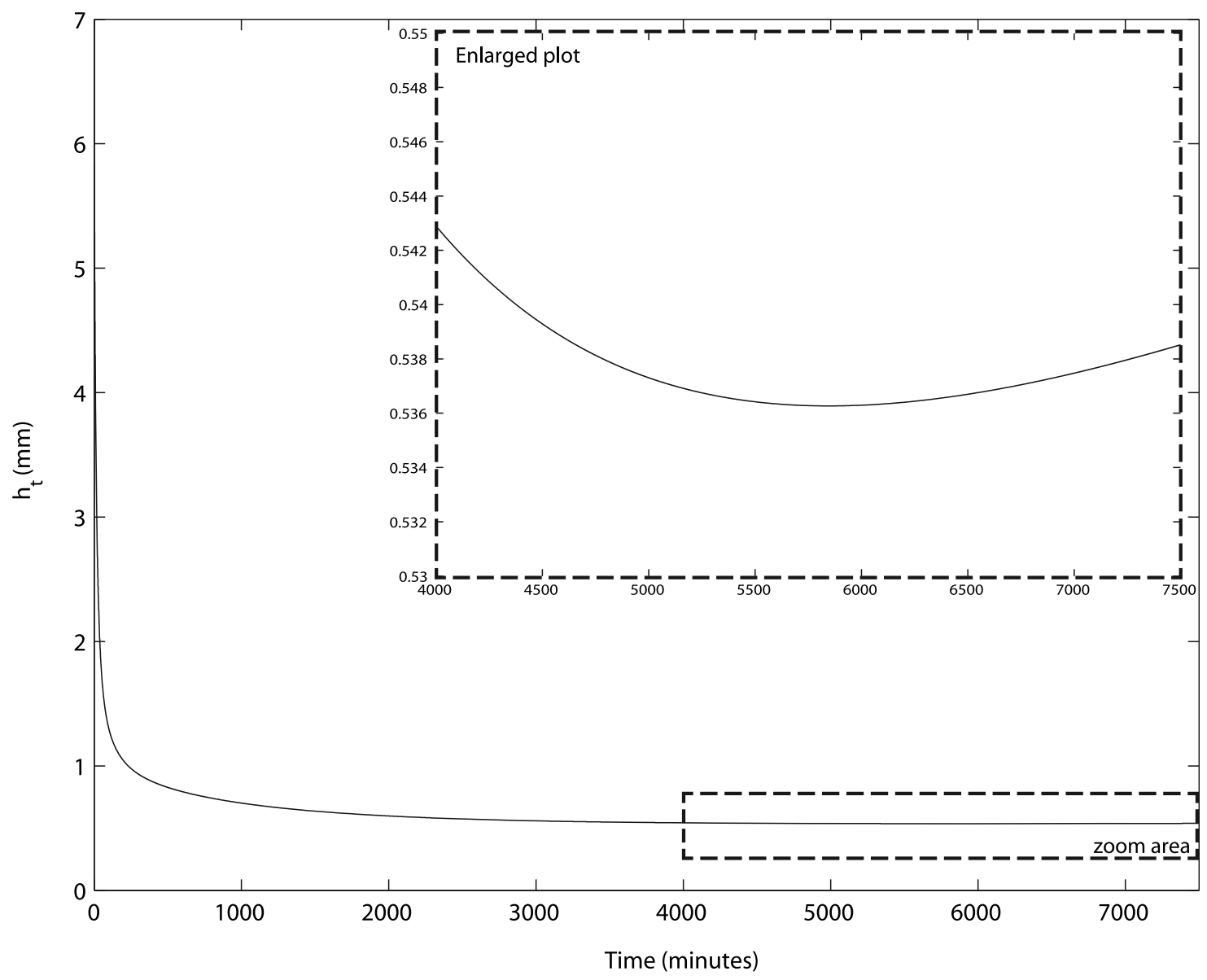

Figure 8. The rate at which the thickness of the liquid layer $\left(h_{\mathrm{t}}\right)$ is reducing with time in minutes when $h_{0}=7 \mathrm{~mm}$. The enlarged plot shows a zoom of the area in the dashed box.

liquid layer through the lower layer ice sheet is enhanced, slowing down consolidation.

[32] Figure 7c shows the model's sensitivity to $S_{\text {bulk }}$. The plot shows that the higher $S_{\text {bulk }}$ is, the larger $C_{\text {time }}$ is. This is because an increase in $S_{\text {bulk }}$ lowers the thermal conductivity of the sea ice and increases its specific heat capacity, which reduces the ability of the sea ice to conduct heat away to the atmosphere, thus retarding the consolidation time.

[33] Figure $7 \mathrm{~d}$ shows that the greater $S_{\text {ocean }}$ is, the greater $C_{\text {time }}$ is. This is because an increase in $S_{\text {ocean }}$ lowers the freezing temperature of the ocean, thereby decreasing the initial temperature gradients in the ice sheets and thus the diffusional heat fluxes through them, so that $C_{\text {time }}$ is increased. In addition, an increase in $S_{\text {ocean }}$ also increases the initial salinity of the liquid layer, such that as consolidation proceeds, the liquid layer gets increasingly salty. At the high salinities reached just prior to the consolidation $(\sim 110 \mathrm{ppt}$ using standard case parameters) the nonlinearity of the liquidus curve causes a greater than linear decrease in the freezing temperature of the liquid layer, which acts to further retard the consolidation time. This is why in Figure $7 \mathrm{~d}$ we see a greater than linear increase in $C_{\text {time }}$ for salinities higher than $\sim 20 \mathrm{ppt}$, despite the fact that it has little effect on the freezing temperature of the ocean.

[34] To explore the uncertainty in the brine release process, the dependence of $C_{\text {time }}$ on $f$ for both the Arctic and north Caspian parameters was investigated while $h_{\mathrm{sa}}$ was held constant at $0.5 \mathrm{~mm}$ (see Figure 7e). As the fraction of salt released into the liquid layer during freezing $f$ increases, the consolidation time increases because the freezing temperature of the liquid layer decreases. Figure 6e shows that for $f$ greater than $35 \%$, there are no points for the Arctic; this is because under these conditions the liquid layer did not consolidate. Conversely, for the north Caspian the effect of varying $f$ from $0 \%$ to $100 \%$ varied the consolidation time between 30 and $1000 \mathrm{~min}$. This is due to the differences in the salinity of the seawater.

[35] Figure $7 \mathrm{f}$ shows the sensitivity of the model to the surface asperity height $h_{\text {sa }}$. Figure $7 f$ shows that the smaller $h_{\mathrm{sa}}$ is, the greater $C_{\text {time }}$ is. This makes sense since the smaller the surface roughness, the greater the quantity of liquid that has to freeze before the asperities can effectively bond.

[36] The sensitivity of the model to the forcing data is shown in Figure 11. Figure 11 shows that $C_{\text {time }}$ is sensitive to the incoming longwave, $F_{\mathrm{LW}}$, and shortwave, $F_{\mathrm{SW}}$, radiation and the sensible $F_{\text {sens }}$ and the latent heat $F_{\text {lat }}$ fluxes and rather insensitive to changes in the oceanic heat flux $F_{\text {ocean. }}$. Since the variation in the radiative fluxes tends to be larger than the variation in the sensible and latent heat fluxes, changes in the radiative fluxes will tend to have a greater influence on the consolidation time. Note that in Figure $11 \mathrm{~b}, F_{\mathrm{SW}}$ is varied only from 0 to $125 \mathrm{~W} \mathrm{~m}^{-2}$. This is 


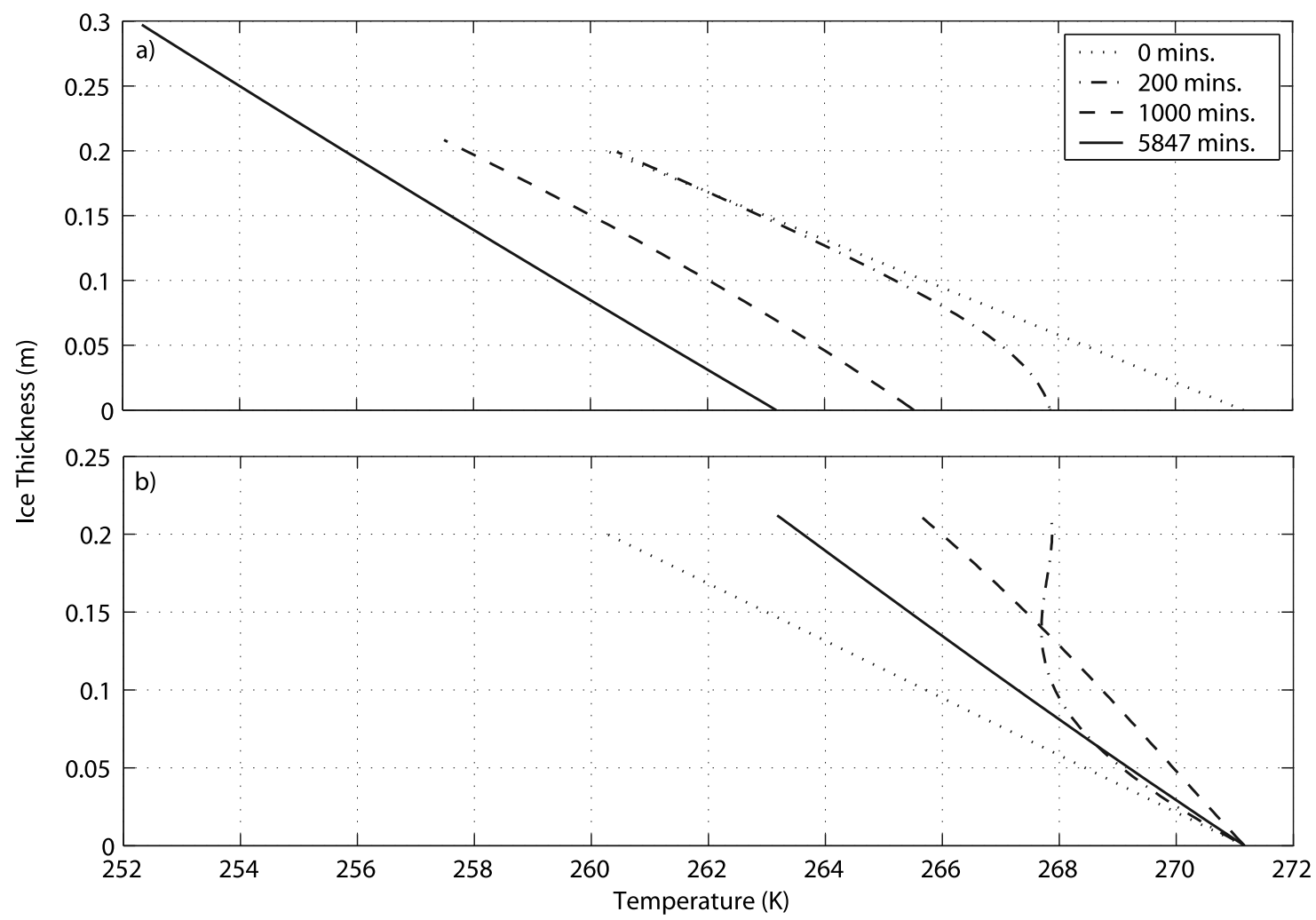

Figure 9. The temperature profiles in the ice sheets when $h_{0}=7 \mathrm{~mm}$. The dotted line shows the initial condition, and the solid line shows the temperature distribution when the liquid layer started to rise.

because for values higher than $125 \mathrm{~W} \mathrm{~m}^{-2}$ the ice sheets did not freeze.

\section{Discussion and Concluding Remarks}

[37] We have presented a one-dimensional, thermal consolidation model for rafted sea ice. Initial runs revealed that when $f$ was greater than zero, the thickness of the liquid layers between the ice sheets reduced asymptotically with time, such that there always remained a thin saline liquid layer. Under these circumstances the ice sheets will never freeze. We therefore proposed a cutoff, such that when the liquid layer reached the size of the surface asperities the adjacent ice sheets could be considered consolidated.

[38] On the basis of our consolidation experiments that were carried out at the HSVA ice basin the surface asperity height was calculated to be between 0 and $1.27 \mathrm{~mm}$. The experiments showed that the salinity of the liquid layer gradually increased with time, therefore indicating that there was a fraction of salt being released into the liquid layer. The fraction of salt that is being released, however, is somewhat uncertain because of the logistics of sampling such a tiny quantity of liquid. Our experimental results showed that prior to the top two layers of a three-layer stack becoming consolidated the salinity had reached 77.3 ppt. This therefore shows that brine is being released from the newly forming sea ice and/or that brine is draining out from the ice sheet above into the liquid layer. We speculate that the mechanism responsible for removing salt from the sea ice is highly localized brine convection at the ice-liquid layer interface.
[39] We considered the consolidation of both two layers and three layers of rafted sea ice. The results showed, using the parameters representative of the north Caspian, Antarctic, and Arctic, that it took about 1,9 , and $15 \mathrm{~h}$, respectively, for two layers of rafted sea ice to consolidate. The consolidation time for three layers of ice in the north Caspian was the same as that for two layers of ice, indicating that there are enough cold reserves within the ice sheets to freeze the liquid layers. Conversely, it took significantly longer for three layers of rafted ice to freeze in the Antarctic $(30 \mathrm{~h})$ and the Arctic $(37 \mathrm{~h})$. The rapid consolidation of rafted ice in the Caspian Sea is due to the low salinity (6 ppt) of the water. Rapid consolidation might also permit subsequent rafting of the consolidated layers and may help to explain the prevalence of multiply rafted ice in the region.

[40] A number of sensitivity studies were conducted to determine the effect variations in model parameters and forcing fluxes had on the consolidation time for simply rafted Arctic sea ice. The results showed that typical variations in the oceanic heat flux and the sensible and latent heat fluxes had little effect on the consolidation time. However, the model was highly sensitive to changes in the initial thickness of the liquid layer $h_{0}$, the ice thickness, the salinity of the ocean, the fraction of salt release during freezing $f$, the surface asperity height $h_{\mathrm{sa}}$, and the downward radiative fluxes. Most of these parameters can be quite well constrained because they have been widely researched; however, $h_{0}, f$, and $h_{\text {sa }}$ are not well known. Therefore, we believe that further investigation of these parameters is needed before any concrete conclusions can be drawn about the rate of consolidation of rafted sea ice features. 


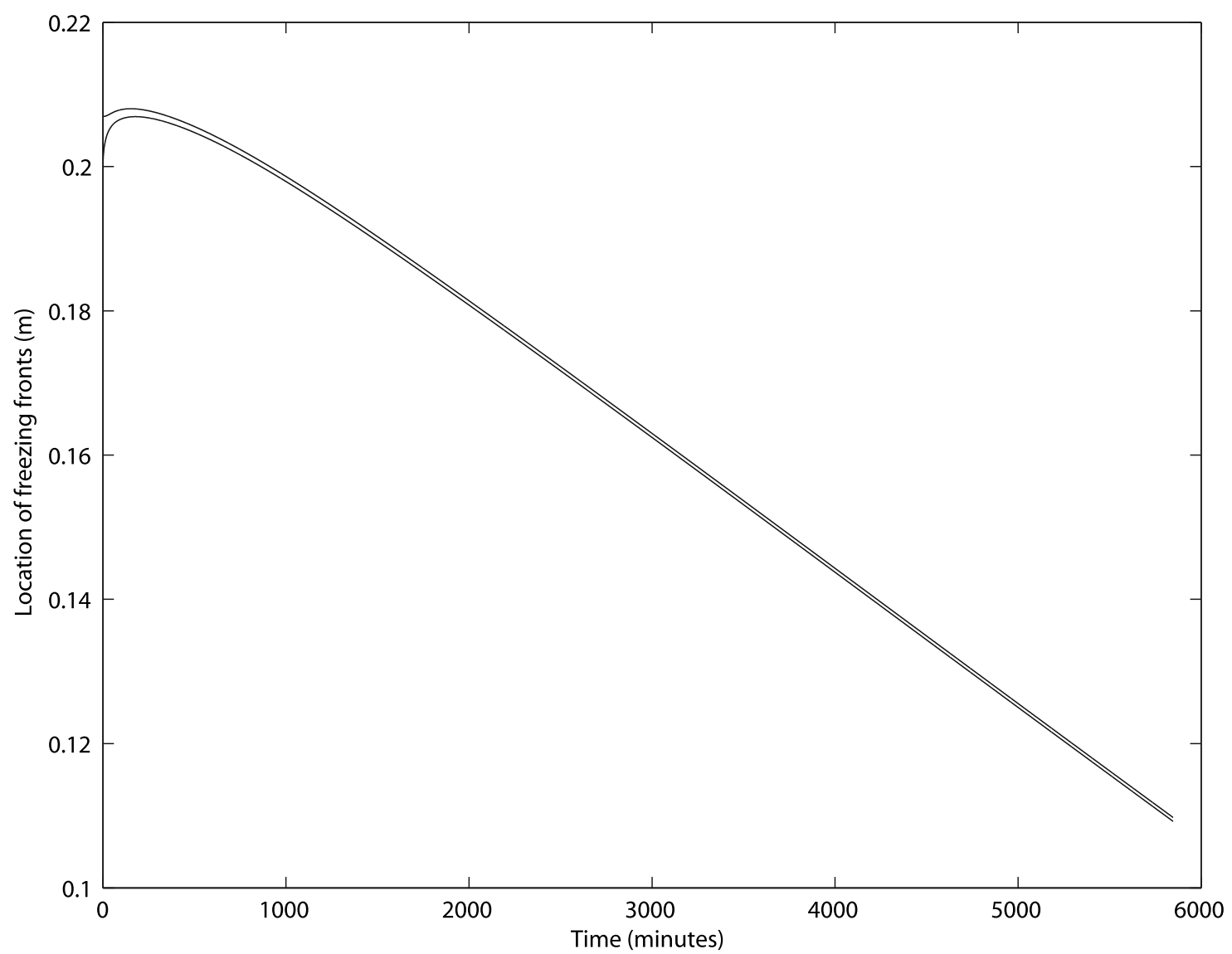

Figure 10. Location of the freezing fronts with time when $h_{0}=7 \mathrm{~mm}$.
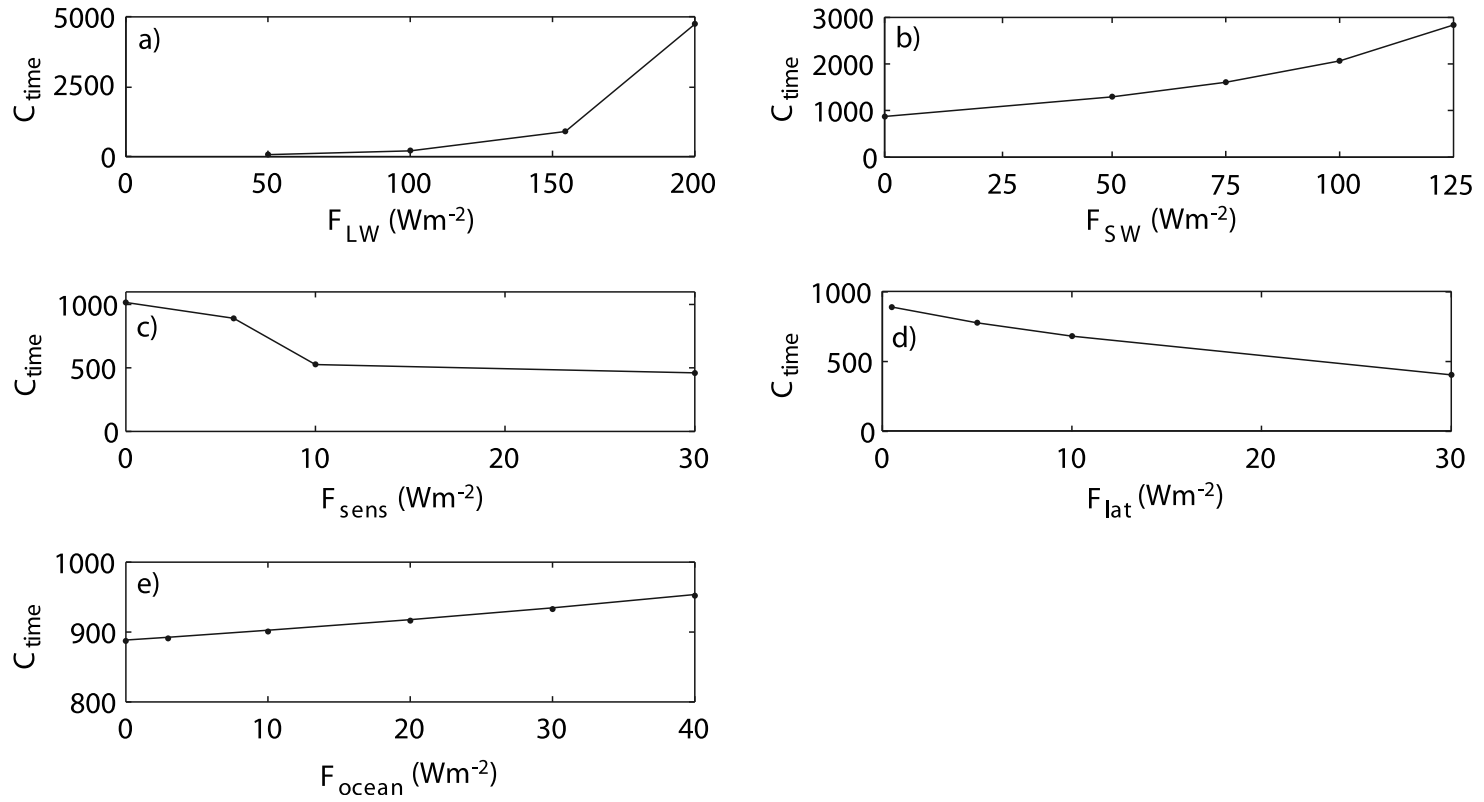

Figure 11. Dependence of the consolidation time $\left(C_{\text {time }}\right)$ in minutes on (a) the downward longwave radiation flux $F_{\mathrm{LW}}$, (b) the downward shortwave radiation flux $F_{\mathrm{SW}}$, (c) the sensible heat flux $F_{\text {sens }}$, (d) the latent heat flux $F_{\text {lat }}$, and (e) the oceanic heat flux $F_{\text {ocean }}$. 
[41] To our knowledge, there is no published experimental work on the consolidation of rafted sea ice, which is surprising considering it is one of the important deformation mechanisms in sea ice. Marchenko and Chenot [2009] carried out some consolidation experiments on drifting ice in the Barents Sea in April 2006. They measured the cohesion between two submerged ice disks that were $\sim 15 \mathrm{~cm}$ in diameter and 3-4 cm thick and found that after a period of 2 days the disks had not frozen together. They also submerged an ice beam that had dimensions of $3 \times 0.5 \times 0.5 \mathrm{~m}$ below level ice and found that after a day it was still possible to move the beam using a shovel. While these results are inconclusive, they suggest that in some circumstances the ice sheets will never consolidate or will take a long time to consolidate.

[42] One of the questions that keeps coming up in discussions on the consolidation process of rafted sea ice is, does brine drainage occur throughout the ice layer? Brine drainage is the name given to density-driven convective overturning of brine within the sea ice and/or the ocean water immediately below the sea ice layer. The effect of brine drainage could be to replace the concentrated brine within the liquid layer with less saline brine, which would allow the liquid layers to freeze at a faster rate.

[43] For brine drainage to occur there needs to be sufficient forcing (e.g., buoyancy forcing), and the ice needs to be sufficiently permeable. The "law of fives" states that if the brine volume of sea ice is greater than $5 \%$, the ice is sufficiently permeable for brine to travel through the ice given sufficient forcing [Golden et al., 1998]. This brine volume corresponds to a temperature warmer than $-5^{\circ} \mathrm{C}$ at a salinity of 5 ppt [Frankenstein and Garner, 1967]. In our model calculations for the Arctic and Antarctic we used a bulk salinity of $5 \mathrm{ppt}$, and the respective temperature plots (Figures 3, 4, and 5) show that the temperature exceeds $-5^{\circ} \mathrm{C}$ only directly above and below the liquid layer and at the iceocean interface. Therefore, on the basis of this law, the ice would only be sufficiently permeable in these regions for brine drainage to occur. (In the case of the north Caspian the low salinity of sea ice means that the ice would not be sufficiently permeable for brine drainage to occur.) In particular, this means that even if a positive hydraulic head is produced during the rafting process, flushing will not occur in the winter cases we consider.

[44] Theoretical and experimental studies on the convection of mushy layers have shown that for convective overturning or gravity drainage to occur in sea ice, the local Rayleigh number must exceed a critical value $R a_{c} \sim 10$ [Worster, 1992, 2000; Wettlaufer et al., 1997; Notz and Worster, 2008]. We therefore calculated the Rayleigh number at different stages during the consolidation process for the Arctic, the Antarctic, and the north Caspian. The results showed that the Rayleigh number did not exceed $R a_{c}$ at any point. Therefore, on the basis of our calculations of the law of fives and the Rayleigh number we believe that there would be no brine drainage during the consolidation process and if there were it would take place only in localized regions directly above and below the liquid layer and at the ice-ocean interface. Certainly, there was no evidence of brine drainage throughout the ice sheets in our experiments in the HSVA. Salinity measurements of sail blocks from an ice ridge in the Barents Sea lend some support to our calculations [Bonnemaire et al., 2003]. The sail blocks consisted of four layers of rafted ice, each $0.3 \mathrm{~m}$ in thickness, and had C-shaped salinity profiles repeating over the thickness of each layer, suggesting that layers of ice had consolidated without brine drainage taking place.

[45] Despite the importance of rafting, it has drawn very little attention in comparison to ridging over the past decade. Given that with the effects of global warming there is expected to be an overall thinning of sea ice in the Arctic [Solomon et al., 2007], rafting and ridging events are likely to increase. Therefore, we believe that a greater understanding of rafted sea ice is going to be of importance in the years to come. We hope that this paper encourages future modeling, experiments, and fieldwork on rafted sea ice to help improve understanding of the consolidation process.

[46] Acknowledgments. We would like to thank Derek Mayne for many useful discussions. Support for this research was provided by the UK Natural Environment Research Council. D. L. Feltham would like to thank the Leverhulme Trust for financial support.

\section{References}

Babko, O., D. A. Rothrock, and G. A. Maykut (2002), Role of rafting in the mechanical redistribution of sea ice thickness, J. Geophys. Res., 107(C8), 3113, doi:10.1029/1999JC000190.

Bitz, C. M., and W. H. Lipscomb (1999), An energy-conserving thermodynamic model of sea ice, J. Geophys. Res., 104(C7), 15,669-15,677, doi:10.1029/1999JC900100.

Bonnemaire, B., K. V. Hoyland, P. Liferov, and P. O. Moslet (2003), An ice ridge in the Barents Sea. Part 1: Morphology and physical parameters in-situ, paper presented at 17th International Conference on Port and Ocean Engineering Under Arctic Conditions, Univ. of Sci. Technol., Trondheim, Norway.

Ebert, E. E., and J. A. Curry (1993), An intermediate one-dimensional thermodynamic sea ice model for investigating ice-atmosphere interactions, J. Geophys. Res., 98(C6), 10,085-10,109, doi:10.1029/93JC00656.

Feltham, D. (1998), Fluid dynamics and thermodynamics of sea ice., Ph.D. thesis, Univ. of Cambridge, Cambridge, U. K.

Feltham, D. L., N. Untersteiner, J. S. Wettlaufer, and M. G. Worster (2006), Sea ice is a mushy layer, Geophys. Res. Lett., 33, L14501, doi:10.1029/ 2006GL026290.

Frankenstein, G., and R. Garner (1967), Equations for determining the brine volume of sea ice from $-0.5^{\circ} \mathrm{C}$ to $-22.9^{\circ} \mathrm{C}, \mathrm{J}$. Glaciol., 6(48), 943-944.

Golden, K. M., S. F. Ackley, and V. I. Lytle (1998), The percolation phase transition in sea ice, Science, 282, 2238-2241, doi:10.1126/science. 282.5397.2238.

Hopkins, M. A., J. Tuhkuri, and M. Lensu (1999), Rafting and ridging of thin ice sheets, J. Geophys. Res., 104(C6), 13,605-13,613, doi:10.1029/ 1999JC900031.

Hoyland, K. V. (2002), Consolidation of first-year sea ice ridges, J. Geophys. Res., 107(C6), 3062, doi:10.1029/2000JC000526.

Marchenko, A., and C. Chenot (2009), Regelation of ice blocks in the water and the air, paper presented at 20th International Conference on Port and Ocean Engineering Under Arctic Conditions, Luleå Univ. of Technol., Luleå, Sweden.

Maykut, G. A., and N. Untersteiner (1971), Some results from a timedependent thermodynamic model of sea ice, J. Geophys. Res., 76(6), 1550-1575, doi:10.1029/JC076i006p01550.

Melling, H., D. R. Topham, and D. A. Riedel (1993), Topography of the upper and lower surfaces of 10 hectares of deformed ice, Cold Reg. Sci. Technol., 21, 349-369, doi:10.1016/0165-232X(93)90012-W.

Notz, D., and M. G. Worster (2008), In situ measurements of the evolution of young sea ice, J. Geophys. Res., 113, C03001, doi:10.1029/ 2007JC004333.

Notz, D., J. S. Wettlaufer, and M. G. Worster (2005), A non-destructive method for measuring the salinity and solid fraction of growing sea ice in situ, J. Glaciol., 51(172), 159-166, doi:10.3189/172756505781829548.

Parmerter, R. R. (1975), A model of simple rafting in sea ice, J. Geophys. Res., 80(15), 1948-1952, doi:10.1029/JC080i015p01948.

Perovich, D. K., and B. Elder (2002), Estimates of oceanic heat flux at SHEBA, Geophys. Res. Lett., 29(9), 1344, doi:10.1029/2001GL014171. 
Poplin, J. P., and A. T. Wang (1994), Mechanical properties of rafted annual sea ice, Cold Reg. Sci. Technol., 23, 41-67, doi:10.1016/0165232X(94)90011-6.

Pounder, E. R. (1965), The Physics of Ice, 151 pp., Pergamon, Oxford, U. K.

Sakazume, S., and N. Seki (1978), Thermal properties of ice and snow at low temperature region, Bull. JSME, 44(382), 2059-2069.

Schwerdtfeger, P. (1963), The thermal properties of sea ice, J. Glaciol., 4(36), 789-807.

Solomon, S., D. Qin, M. Manning, Z. Chen, M. Marquis, K. B. Averyt, M. Tignor, and H. L. Miller (Eds.) (2007), Climate Change 2007: The Physical Science Basis: Contribution of Working Group I to the Fourth Assessment Report of the Intergovernmental Panel on Climate Change, 996 pp., Cambridge Univ. Press, Cambridge, U. K.

Taylor, P. D., and D. L. Feltham (2004), A model of melt pond evolution on sea ice, J. Geophys. Res., 109, C12007, doi:10.1029/2004JC002361.

Timco, G. W., and R. M. W. Frederking (1996), A review of sea ice density, Cold Reg. Sci. Technol., 24, 1-6, doi:10.1016/0165-232X(95) 00007-X.

Toyota, T., T. Kawamura, K. I. Ohshima, H. Shimoda, and M. Wakatsuch (2004), Thickness distribution, texture and stratigraphy, and a simple probabilistic model for dynamic thickening of sea ice in the southern Sea of Okhotsk, J. Geophys. Res., 109, C06001, doi:10.1029/ 2003JC002090.

Tuhkuri, J., and M. Lensu (2002), Laboratory tests on ridging and rafting of ice sheets, J. Geophys. Res., 107(C9), 3125, doi:10.1029/2001JC000848.

Vella, D., and J. S. Wettlaufer (2007), Finger rafting: A generic instability of floating elastic ice sheets, Phys. Rev. Lett., 98, 088303, doi:10.1103/ PhysRevLett.98.088303.

Vella, D., and J. S. Wettlaufer (2008), Explaining patterns formed by ice floe interactions, J. Geophys. Res., 113, C11011, doi:10.1029/ 2008JC004781.
Weast, R. C. (1971), Handbook of Chemistry and Physics, 52nd ed., Chem. Rubber Co., Cleveland, Ohio.

Weeks, W. F., and S. F. Ackley (1986), The growth, structure and properties of sea ice, in The Geophysics of Sea Ice, NATO ASI Ser., Ser. B., vol. 146, edited by N. Untersteiner, pp. 9-164, Martinus Nijhoff, Dordrecht, Netherlands.

Weeks, W. F., and A. Kovacs (1970), On Pressure Ridges, CRREL Rep. IR505, 59 pp., U.S. Army Cold Reg. Res. and Eng. Lab., Hanover, N. H. Wettlaufer, J. S., M. G. Worster, and H. E. Huppert (1997), Natural convection during solidification of an alloy from above with application to the evolution of sea ice, J. Fluid Mech., 344, 291-316, doi:10.1017/ S0022112097006022.

Woods, A. W. (1992), Melting and dissolving, J. Fluid Mech., 239 429-448, doi:10.1017/S0022112092004476.

Worby, A. P., M. O. Jefferies, W. F. Weeks, K. Morris, and R. Jana (1996), The thickness distribution of sea ice and snow cover during the late winter in the Bellingshausen and Amundsen seas, Antarctica, J. Geophys. Res., 101(C12), 28,441-28,445, doi:10.1029/96JC02737.

Worster, M. G. (1992), The dynmics of mushy layers, in Interactive Dynamics of Convection and Solidification, edited by S. H. Davis et al., pp. 113-138, Kluwer Acad., Dortrecht, Netherlands.

Worster, M. G. (2000), Solidification of fluids, in Perspectives in Fluid Mechanics, edited by G. K. Batchelor et al., pp. 393-446, Cambridge Univ. Press, Cambridge, U. K.

E. Bailey and P. R. Sammonds, Rock and Ice Physics Laboratory, Department of Earth Sciences, University College London, Gower Street, London WC1E 6BT, UK. (e.bailey@ucl.ac.uk)

D. L. Feltham, Centre for Polar Observation and Modelling, National Centre for Earth Observation, Department of Earth Sciences, University College London, Pearson Building, Gower Street, London WC1E 6BT, UK. 